\title{
Heartsink relationships: paradox as paradigm
}

\section{ALVIN, BERNARD, AND STEPHANA}

\section{A heartsink trio}

Alvin sat in the consulting room, crutches against the wall behind him, and picked ineffectively at a band-aid on his cheek. His physician entered the room, reluctantly.

\author{
'I'd like you to look at this spot on my \\ face'. \\ 'OK, just remove the band-aid.' \\ 'I can't. My finger nails are too short.'
}

Alvin giggled. The physician sighed.

He approached (but not too closely), and removed the dressing with the extreme tips of his fingers. He washed his hands, approached again, and peered at the pimple from a distance.

\section{'I stuck a needle in it last night.'}

The physician sighed, yet again. On closer inspection, (but still not too much closer), the pimple turned out to be a small, infected sebaceous cyst. Hands were washed again.

'It looks like a small sebaceous cyst, that has got infected, Alvin.'

'A cyst! How would I get that?'

'Alvin, what's the big deal. It's only a cyst.'

'You sound just like my father!'

'What does that mean?'

Alvin's story was revealing. He was the son of an abusive father, and had left home and school at the age of 15 . He approached life tentatively, and with good reason, He had spent various periods of time in psychiatric institutions and in jail, and was a client in a methadone clinic. His life was marked by drug-induced psychotic episodes, and conflicts with the police, with men, and with women. Inevitably, he fared poorly when these conflicts became physical. For example, 1 month prior to his latest office visit, Alvin had been 'sent packing' by his wife after a particularly fierce argument. In a fit of frustration, he had insisted on removing a small refrigerator from their apartment, had fallen while trying to negotiate a flight of stairs, and had sustained a broken leg when the appliance fell on top of him.

$$
\text { **** }
$$

Bernard turned up for his regular visit, and as usual, delivered a litany of woes; why him, why couldn't he find a girlfriend, why did epilepsy stop him from having a social drink, why did employers get rid of him, why why why?

The physician looked into space, and thought of other things. It was his usual way of dealing with Bernard's relentless detail, passivity and lack of progress. Partly too, he felt put upon by his partners, who had referred Bernard to him as a 'challenge' without acknowledging the difficulties they had in managing him:

\section{'Bernard, just why are you here?'}

The physician's tone was sharp.

\section{'Because I have to be. You understand me.'}

The physician felt he understood nothing, but thought he should live up to the expectation placed on him, and over time, explored Bernard's story.

Born into a large family, Bernard's mother died when he was 3 years of age. In his early teens, he was diagnosed with epilepsy which made its presence felt at the most inopportune times. He was tolerated rather than respected by his family and care-givers, and the physician felt more should be done. He referred Bernard for psychological assessment, where he was treated with something less than charity. Shortly thereafter, he was killed when crossing a railway track.

$$
\text { **** }
$$

Stephana was 74 years old, unhappily married, and beset by pain in the muscles of her arms and chest, and in her abdomen. She had chronic and persistent headaches. Despite her discomforts, she walked gracefully, and dressed with style. Her voice, however, was one that carried its own weight of suffering and hurt.

One day when she was describing her headache in her usual way, the physician found himself gazing into space, daydreaming. He began to set an agenda for a meeting. He wondered what he would have for lunch. Then he became aware of what was happening:

'Stephana, I'm not doing a very good job of listening to what you have to say. I apologise.'

'It's alright; it's the story of my life.' 'How so?'

Her voice dropped, and softened.

'You know, doctor, I came to Canada when I was 18, from Sofia. Chris bought me for his bride. He was much older than I. I wanted to study music, but there was no money. From the day I arrived, until now, he never called me by my name. It's 'you' this, and 'you' that, never Stephana. We haven't been together since our daughter was born. I haemorrhaged, and had to have a hysterectomy. He thought I was dirty, or something.'

Her story, and its power, brought silence to the consulting room:

'What can I say?'

'You don't have to say anything. It helps that you listen. He never did.'

The physician took another step:

'You know, Stephana, I want to admit something to you. I know it's my problem, but your voice has a powerful effect on me. It makes me feel helpless, and I just seem to turn off.' 'Oh that! My daughter calls it the 'doom' voice'. 
'Heartsink patients' are an important and challenging part of practice life. The term was coined by O'Dowd, ${ }^{1}$ who used it to describe patients who provoked negative emotional reactions in their physicians. O'Dowd went on to describe the general characteristics of such patients in terms of medical diagnoses, but pointed out that these patients were really more readily identified by physician reaction.

Mathers, ${ }^{2}$ on the other hand, explored those physician characteristics that were associated with such experiences, and reported a set of four explanatory variables that were accountable for $60 \%$ of the variance in the numbers of heartsink patients on GPs' lists; a perception of greater perceived workload, lower job satisfaction, lack of training in communication skills, and lack of postgraduate training.

Previously, others have focused on the task of classifying and categorising patients, but the point has been made repeatedly; that heartsink experiences can be quite idiosyncratic. It seems reasonable, therefore, to conclude that the idiosyncrasy lies properly within the relationship itself, and what is being experienced, are heartsink relationships. Further, the experiences with Alvin, Bernard, and Stephana can help shed light on the underlying mechanisms, which lead to management options.

Alvin, Stephana, and Bernard had been avoided, tuned out, controlled, and patronised, within their personal lives. All three patients were on the receiving end of personal physician responses, perhaps better described as impulsive reactions, which owed more to the virtue of honesty, than skill. An exploration of these patients' life experiences led to an understanding that they, the physicians, were playing out a script that had been written many years before; a script of behaviours and reactions, of self-fulfilling prophesies. If it can be taken as a given that within the context of relationships, impulsive behaviours have their roots in unconscious fears, then particular impulses may have particular meaning.

For example, Alvin, with his giggles and inability to remove a band-aid, was 'put down', and treated by his doctor, as a child. Wouldn't that be exactly the reaction he would dread? But expect?

Stephana, with her litany of woes and shrill voice, was tuned out. Wouldn't that be exactly the reaction she would dread? But expect?

Bernard, with his list of dissatisfactions, was not respected, not taken seriously. Wouldn't that be exactly the reaction he would dread? But again, expect?

These patients' fears were associated with self-defeating behaviours, and these behaviours provoked negative impulsive reactions. Such self-fulfilling prophecies might be paraphrased as follows:

'What people fear most is what they pull for, and what they get.' (J Wallace, personal communication, 1985).

This is at least an irony, if not a paradox, and the three elements of fear, behaviour and reaction, offer more than a paradigm of understanding. They offer communication options. For example, a physician's impulses can be talked about, the patient's mannerisms can be addressed, and patient and/or physician fears can be the subject of conversation as was the case with Alvin, Bernard, and Stephana. In Contracting for Trust in Family Practice Obstetrics, Klein ${ }^{3}$ described an experience where he became frustrated by a patient's endless list of questions about her pregnancy. So much so, that he finally addressed directly his patient's fears about his competence, and having her baby delivered by a family physician and not a specialist. He mentioned that he thought her presentation of questions indicated a lack of trust. Out of that and other similar experiences, he developed an approach:

'Mrs. X, I am worried about your list. I support the items on the list and the philosophy behind them. What worries me, however, is the list itself. In my experience, women who have such a list too frequently get what they don't want, and wind up unhappy with their doctor, and themselves. I think the list is about fear, and the fact that you don't know me well enough yet, to trust me.'

More recently, a relationship-centered care initiative $e^{4}$ has recognised that the nature and quality of relationships are central to health care and healthcare delivery, and within that context, four principles were seen as foundation stones:

- that relationships in health care ought to include the personhood of the participants;

- that affect and emotion are important components of these relationships;

- that all healthcare relationships occur in the context of reciprocal influence; and

- that the formation and maintenance of genuine relationships in health care is morally valuable.

Family physicians and GPs have always subscribed to such principles and have found their own ways of advancing them. The paradox represents, quite simply, an approach to situations where these principles are in jeopardy. Should we constantly look behind our initial feelings, tackle the emotions of our patients more deeply, and realise the power of our own feelings upon our patients?

\section{Neil Grant and Trevor Gibbs}

\section{REFERENCES}

1. O'Dowd TC. Five years of heartsink patients in general practice. BMJ 1988; 297: 528-530.

2. Mathers N, Jones N, Hannay D. Heartsink patients: a study of their general practitioners. Br J Gen Pract 1995; 45: 293-296.

3. Klein M. Contracting for trust in family practice obstetrics. Can Fam Physician 1983; 29: 2225-2227.

4. Beach MC, Inui T. Relationship-centered Care Research Network. Relationship-centered care. A constructive reframing. J Gen Intern Med 2006; 21 Suppl 1: S3-8.

DOI: 10.3399/bjgp09X406983 